Revista Brasileira de Farmacognosia Brazilian Journal of Pharmacognosy 22(4): 868-873, Jul./Aug. 2012

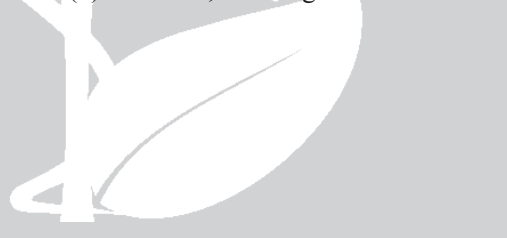

Article

Received 28 Oct 2011

Accepted 2 Jan 2012

Available online 21 Jun 2012

Keywords:

GIS

site selection

seaweeds

Gracilaria birdiae

multi-criteria evaluation

ISSN 0102-695X

http://dx.doi.org/10.1590/S0102-

695X2012005000087

\section{Use of geographic information systems (GIS) to identify adequate sites for cultivation of the seaweed Gracilaria birdiae in Rio Grande do Norte, Northeastern Brazil}

\author{
Flavo E. S. de Sousa, ${ }^{1}$ Euriel A. Moura, ${ }^{2}$ Eliane Marinho- \\ Soriano ${ }^{*}, 2$ \\ ${ }^{1}$ Escola Agrícola de Jundiai, Universidade Federal do Rio Grande do Norte, \\ Brazil, \\ ${ }^{2}$ Departamento de Oceanografia e Limnologia, Universidade Federal do Rio \\ Grande do Norte, Brazil.
}

\begin{abstract}
This study was designed to select potential areas for cultivation of the seaweed Gracilaria birdiae Plastino \& E.C. Oliveira (Gracilariales, Rhodophyta) on the coast of Rio Grande do Norte state, Brazil. The Geographic Information System (GIS) and multi-criteria evaluation (MCE) were used to identify the most suitable areas. The Analytical Hierarchical Process (AHP) was applied to establish MCE weights, thereby generating viable areas for species cultivation. From a total of $3316.82 \mathrm{ha}$, around $53.67 \%$ (1780.06 ha) were indicated as highly suitable areas, $40.93 \%$ (1357.58 ha) as moderately suitable and 5.40\% (179.18 ha) as scarcely suitable for seaweed cultivation. Seven areas (1084.62 ha) are located on the northern coast and 20 (2232.20 ha) on the eastern coast. The results show that GIS can be used as an effective instrument for selecting seaweed cultivation areas.
\end{abstract}

\section{Introduction}

The use of seaweeds as human food, animal forage, fertilizers, phycocolloids and as natural feed for economically important species in aquaculture has received considerable attention in several parts of the world. Moreover, recent studies have shown new opportunities, particularly in the field of biotechnology, related to the bioactive properties of molecules extracted from seaweeds for therapeutic drug manufacture. However, a large number of these seaweeds are derived from natural beds and indiscriminate harvest, can affect the equilibrium of natural populations. A viable alternative, capable of avoiding depletion of natural stocks without compromising supplies, is the establishment of cultures of species that can ensure large scale seaweed production.

Species of the genus Gracilaria produce agar, a phycocolloid used in a number of industries (food, cosmetic, pharmaceutical). Due to its economic importance, it is one of the most cultivated genera worldwide (Buschmann et al., 2008). Several species are found in Brazil, especially on the northeastern coast, where species are collected and sold by fishing communities (Marinho-Soriano et al., 2006). A recent pilot project for $G$. birdiae cultivation conducted on the coast of Rio Grande do Norte showed significant growth rates (Bezerra \& Marinho-Soriano, 2010) and can be used as a reference for implementing large-scale cultivation in Northeast Brazil.

Suitable sites must be selected to ensure successful sustainable development of a mariculture undertaking. Selecting a culture area is one of the most important aspects of any aquaculture operation (Nath et al., 2000; Giap et al., 2005). Environmental, physical and socioeconomic aspects of the sites must be carefully assessed before establishing the enterprise. Among the environmental characteristics are climate (wind, rain, temperature and light) and water quality (nutrients, temperature, salinity, turbidity, $\mathrm{pH}$, dissolved oxygen). With respect to physical characteristics, the type of submersed bottom, coastline, tides, currents and depth must be considered. The main socioeconomic aspects encompass social organization, number of individuals involved in the activity, population density and market conditions. All the aforementioned factors are important for the success of the business. However, in some cases, one parameter could exert more influence than another, which may influence site selection (Beveridge et al., 1994).

GIS (Geografical Information System) has been described as an efficient tool for identifying and quantifying suitable aquaculture sites (Nath et al., 
2000). Indeed, all activities involving the collection of spatial distribution data can benefit from such systems. In practice, through the use of databases, society can have access to a set of information that allows effective environmental management planning. In countries such as Brazil, with a lack of adequate information for decision-making on urban, rural and environmental issues, geoprocessing has a huge potential (Felgueiras \& Câmara, 1993). This study was conducted in order to identify appropriate sites for the farming of seaweed (G. birdiae) in Rio Grande do Norte, Northeast Brazil.

\section{Materials and Methods}

\section{Description of the study area}

The study was conducted on the coast of the state of Rio Grande do Norte, located in the Northeast of Brazil (Figure 1). The climatic conditions of the study area are directly related to meteorological indicators such as wind speed and direction, irradiance, rainfall, and atmospheric temperature. Ocean circulation is dominated by the Brazil current (north-south direction) and the Equatorial current (east-west direction). The shelf is narrow and shallow, which causes a decrease in tide currents and an increase in coastal currents. The relief of the shelf is relatively flat, interspersed with undulations and features typical of reefs and coralline algae. Water temperature varies between 25 and $28^{\circ} \mathrm{C}$, and salinity between 35 and 37 psu throughout the year.

The coast of Rio Grande do Norte is approximately $410 \mathrm{~km}$ long and is characterized by coral and sandstone reefs. In some areas, the reefs extend in a long strip parallel to the coast, providing an effective protection against wave action. This environment has a wide diversity of seaweeds, several of which have recognized economic potential (Marinho-Soriano, 1999).

The Rio Grande do Norte coast is divided into two distinct sectors, the northern $\left(04^{\circ} 50^{\prime} \mathrm{S}-37^{\circ} 15^{\prime} \mathrm{W}\right.$ to $\left.05^{\circ} 05^{\prime} \mathrm{S}-35^{\circ} 40^{\prime} \mathrm{W}\right)$ and the eastern $\left(05^{\circ} 05^{\prime} \mathrm{S}-35^{\circ} 40^{\prime} \mathrm{W}\right.$ to $\left.06^{\circ} 30^{\prime} \mathrm{S}-34^{\circ} 58^{\prime} \mathrm{W}\right)$ coasts. The northern coast has a high number of sunlight hours $(2600 \mathrm{~h} /$ year) and mean temperatures around $27^{\circ} \mathrm{C}$. The wind direction is predominately from E-NE, a mean velocity of $6.5 \mathrm{~m} / \mathrm{s}$ from April to August, increasing to $9 \mathrm{~m} / \mathrm{s}$ from August to September. The waves are generally from the east, ranging from 0.5 to $1.0 \mathrm{~m}$, with periods lasting from 5 to $8 \mathrm{~s}$. As a result of the position of the coast and the wind direction, an important long shore current, that determines all sediment movement in the region, flows along the coast in an E-W direction. Temperatures are milder in the eastern region (mean $25^{\circ} \mathrm{C}$ ). Winds originating in the South Atlantic (trade winds) and responsible for the high rainfall indices $(1400 \mathrm{~mm} /$ year) have a mean velocity of $4.5 \mathrm{~m} / \mathrm{s}$ throughout the year, with a predominately SE-NW direction.

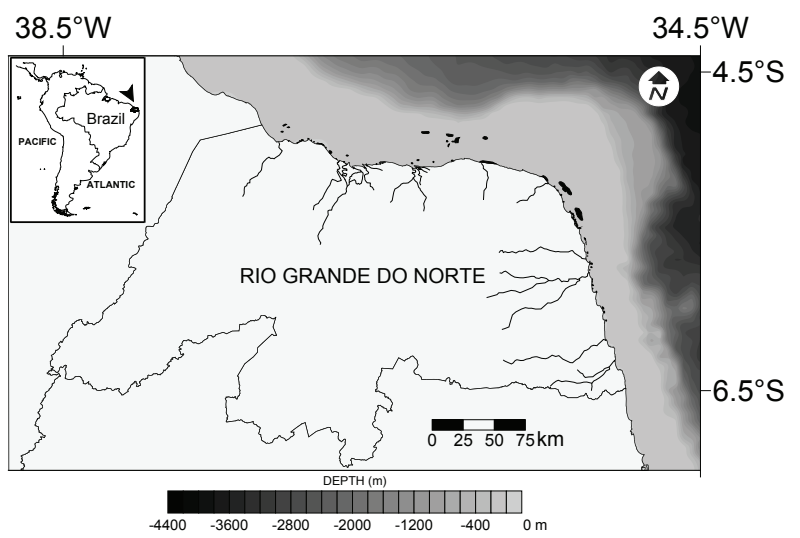

Figure 1. Study area location in the Rio Grande do Norte State, Northeastern Brazil. The black spots indicate the seaweed beds.

\section{Map generation criteria}

The criteria used to select seaweed cultivation areas were waters sheltered from waves and currents with a depth ranging between 1.0 and $3.0 \mathrm{~m}$. Spatial analysis of data related to current and wind direction was performed with the support of the GIS database using IDRISI kilimanjaro v.14.02 (Clark Labs, Worcester, MA, USA). The map of the coastline illustrating the magnitude of currents and waves was obtained by vectorizing orbital SPOT/HRV-1 images, XS1, XS2 and XS3 bands, with a spatial resolution of $20 \mathrm{~m}$, and enhanced by RGB 321 color composition (Red; Green; Blue). Images were georeferenced by using coordinates obtained from official topographic charts of the Rio Grande do Norte coast, produced by SUDENE on a scale of $1: 100000$.

Due to the difference in incidence of winds and currents between the Northern and Eastern coast of Rio Grande do Norte, a distance operator (Disperse) was applied over features of the eastern coast, with wind direction of $45^{\circ} \mathrm{SE}$ and currents $0^{\circ} \mathrm{N}$. Zones displaying the lowest magnitudes of exposure to current speeds and direction were delimited and selected as sheltered coastal areas. Delimited areas were adjusted for isobaths from 1.0 to $3.0 \mathrm{~m}$ using digitalized nautical charts of the Rio Grande do Norte coast obtained from of the Brazilian Navy, with Carta-Linx support vector (Clark Labs, Worcester, MA, USA).

The main criteria (factors) used in this study were the following: accessibility (main and secondary roads), urban areas, proximity of districts, main city and market, distance from estuaries, coastline, and seaweed beds. Thematic charts were produced from topographical maps (SUDENE - scale 1:100000) and 
nautical charts (Brazilian Navy). These maps were updated using SPOT/HRV-1, images developed by INPE (Brazilian Space Agency).

The cost distance map was obtained by using the cost analysis module (Cost) in IDRISI. The determination of time connecting cultivation areas to the market was obtained by integrating the map of roads connecting cultivation areas, with urban centers and the main city. The friction coefficients applied were 1.0 for main roads and 2.5 for secondary roads, indicating a journey time two and a half times longer than on main roads. For access without roads, a friction coefficient of 10.0 was used. After the definition of criteria and the compilation of maps, the fuzzy concept was used to standardize the factors for a continuous suitability scale from 1 (least suitable) to 8 (most suitable) for the development seaweed cultivation. Weighing and suitability ratings were based on the level of importance of a particular factor that influences seaweed mariculture. The range of areas characteristics was divided into three classes: highly suitable, moderately suitable and scarcely suitable.

\section{Weighting procedure}

The development of weights was based on a pairwise comparison matrix according to the Analytical Hierarchy Process (AHP) of Saaty (1977), which is one of the most common weighting techniques in multicriteria evaluation (MCE). The principal eigenvector of the pairwise comparison was analyzed to produce a set of weights that sum 1 (Table 1). The factors and their resulting weights can then be used in the MCE module to identify feasible areas for seaweed farming. In the pairwise comparison, the relative importance of the criteria was evaluated on a continuous scale from least important $(1 / 9,1 / 7,1 / 5 \ldots 1 / 2)$ to most important $(1,2,3 \ldots 9)$. This procedure enabled calculation of the consistency ratio for weight distribution between factors. A consistency ratio of 0.1 was obtained, considered acceptable for weight distribution of each criteria or factor (Saaty, 1977; Banai-Kashani, 1989).

\section{Results and Discussion}

The present study identified promising sites for the implantation of seaweed cultivation in Rio Grande do Norte State. Of the total area analyzed (3316.82 ha), approximately $53.67 \%$ (1780.06 ha) was considered to be highly suitable, 40.93\% (1357.58 ha) moderately suitable and $5.40 \%$ (179.18 ha) scarcely suitable for seaweed cultivation. Of this total (3316.82 ha), seven areas (1084.62 ha) are located on the northern coast and 20 (2232.20 ha) on the eastern coast (Figure 2$)$. Although smaller in number, the northern coastal regions that are suitable for seaweed cultivation are larger (mean of 155 ha) than those on the eastern coast (mean of 110 ha). The most promising sites for cultivation, identified by GIS, are shallow and relatively protected from wave action. They are situated at a depths ranging between $0.1 \mathrm{~m}$ and $3.0 \mathrm{~m}$ considering the lowest and highest point of the spring tide. For farming implementation, a maximum seaward limit of $1000 \mathrm{~m}$ from the coast was used. Greater distances are operationally unviable, burdening production costs.

The development of mariculture is affected by several factors, including environmental and socioeconomic factors (Nath et al., 2000; Radiarta et al., 2011). This study focuses on the physical and socio-economic aspects. Among the criteria analyzed, some are of paramount importance, such as conditions of coastal shelter (winds, currents, waves etc.), proximity to algae beds and distance from roads. These last two criteria are important in obtaining seeds for cultivating and marketing the product. Spatial criteria from the fuzzy concept were standardized to reflect the best conditions for successful production in the region. Distances adopted represent a scenario of optimal environmental and operational conditions. These factors were adjusted according to verification in the field so as to identify areas with more or less potential and their restrictions.

Table 1. Pairwise comparison matrix for assessing the relative importance of parameters for seaweed cultivation in Rio Grande do Norte, Brazil.

\begin{tabular}{|c|c|c|c|c|c|c|c|c|c|}
\hline Parameters & $\begin{array}{l}\text { Distance to } \\
\text { natural beds }\end{array}$ & $\begin{array}{l}\text { Distance } \\
\text { seaward }\end{array}$ & $\begin{array}{l}\text { Distance } \\
\text { to market }\end{array}$ & $\begin{array}{l}\text { Distance } \\
\text { to districts }\end{array}$ & $\begin{array}{l}\text { Distance } \\
\text { to estuary }\end{array}$ & $\begin{array}{c}\text { Distance } \\
\text { to road }\end{array}$ & $\begin{array}{c}\text { Distance to } \\
\text { main city }\end{array}$ & $\begin{array}{l}\text { Distance to } \\
\text { urban areas }\end{array}$ & Weights \\
\hline Distance to natural beds & 1 & & & & & & & & 0.0351 \\
\hline Distance seaward & 3 & 1 & & & & & & & 0.0423 \\
\hline Distance to market & 5 & 5 & 1 & & & & & & 0.1949 \\
\hline Distance to districts & 3 & 3 & $1 / 5$ & 1 & & & & & 0.0599 \\
\hline Distance to estuary & 5 & 5 & $1 / 3$ & 5 & 1 & & & & 0.1333 \\
\hline Distance to road & 1 & 3 & $1 / 3$ & 1 & $1 / 3$ & 1 & & & 0.0502 \\
\hline Distance to main city & 5 & 5 & 1 & 5 & 3 & 7 & 1 & & 0.2357 \\
\hline Distance to urban areas & 3 & 3 & 3 & 3 & 3 & 7 & 1 & 1 & 0.2486 \\
\hline
\end{tabular}




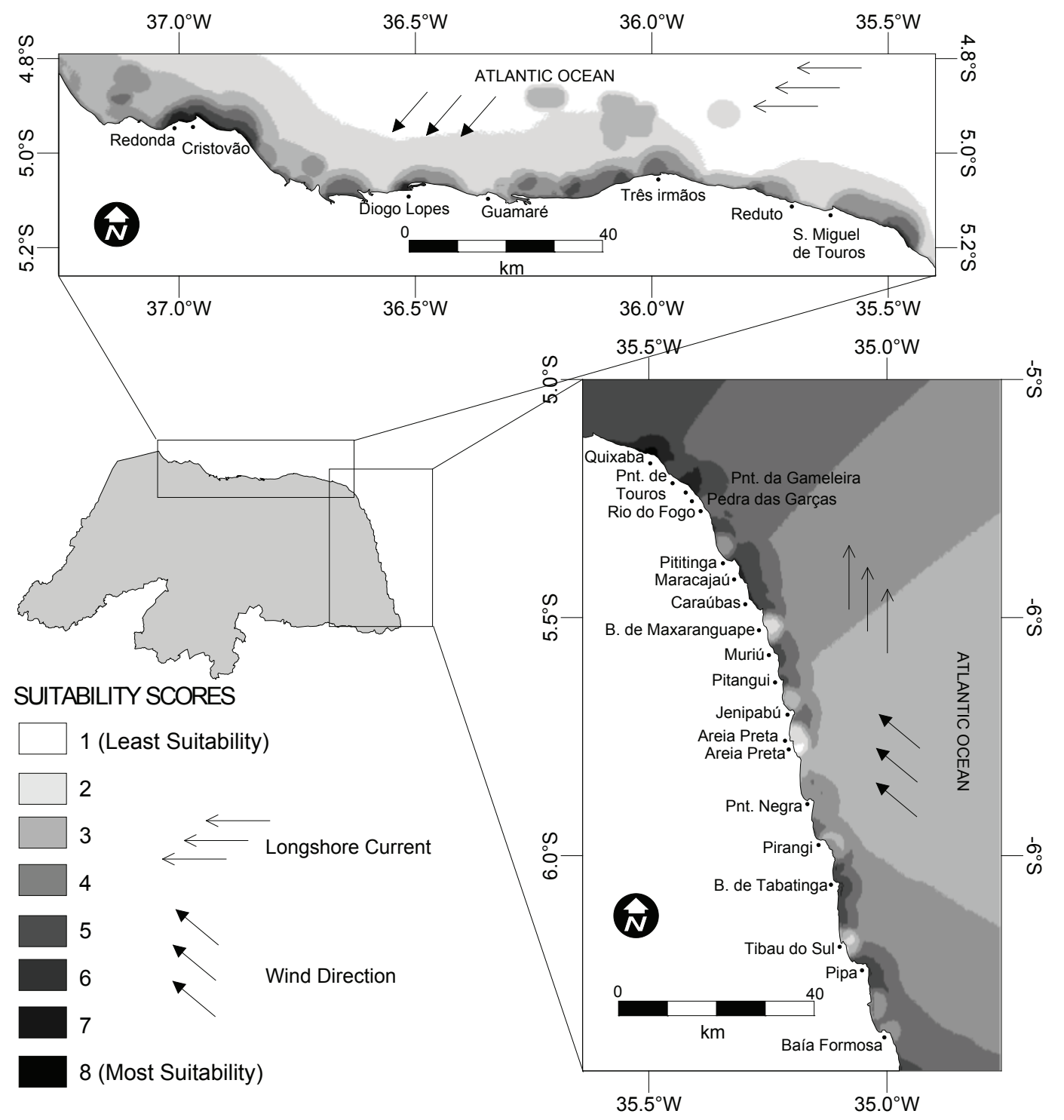

Figure 2. Suitability maps for seaweed cultivation development in Rio Grande do Norte, Brazil.

In relation to environmental aspects, the attribute "sheltered areas" received the highest score and limited some northern coastal regions of Rio Grande do Norte. Identifying sheltered areas considered physical conditions of the water column, such as current speed, wave height and wind speed. These criteria have considerable impact on this part of the coast, particularly between August and September when there is a considerable increase in wind speed (mean of $9 \mathrm{~m} / \mathrm{s}$ ), which directly affects the formation, height and weight of waves. Knowledge regarding the hydrodynamics of a certain area may define the type of cultivation system (raft, cages, long-lines etc.). In addition, ocean currents, strong winds and high waves can damage the seaweed and destroy cultivation structures. Ideal conditions for seaweed cultivation for the region were wind speeds below $4.5 \mathrm{~m} / \mathrm{s}$, current speed of $3 \mathrm{~m} / \mathrm{s}$ and wave heights of $1.0 \mathrm{~m}$. The criterion "wave action protection" was also considered to be the principal factor in selecting areas for the cultivation of oysters on Margarita Island, Venezuela (Buitrago et al., 2005) and seaweeds in Bali, Indonesia (Sulma et al., 2008).

AHP (Analytical Hierarchy Process) results showed greater weights for distance from urban areas (0.2486), distance from the main city (0.2357), distance from the market (0.1949) and distance from estuaries (0.1333). The lowest coefficients obtained were for distance from districts $(0.0599)$, roads $(0.0502)$, seaward (0.0423), and seaweed beds (0.0351). The coefficient for the consistency ratio of weight distribution $(r=0.1)$ was considered to be acceptable. The map resulting 
from MCE (multi-criteria evaluation), generated with eight classes of potential through a weighted linear combination of the weights obtained by AHP, indicated that all regions sheltered from the coast achieved scores ranging from 3 to 8 .

The combination of all parameters in terms of environmental and operational conditions for seaweed farming showed that $53.67 \%$ of the areas analyzed were classified with scores of 8 and 7 (highly suitable), $40.93 \%$ scored 6 and 5 (moderately suitable) and only $5.40 \%$ of the regions received scores of 4 and 3 (scarcely suitable). No areas scored 1 or 2 . These results are in accordance with previous studies using MCE. For example, Radiarta et al. (2008) used multi-criteria evaluation based on GIS to identify sites suitable for Japanese scallop aquaculture (Mizuhopecten yessoensis). More recently, another investigation was conducted using MCE to select locations for the cultivation of Laminaria japonica in Southeast Hokkaido, Japan (Radiarta et al., 2011).

The present study found that areas situated more than $5000 \mathrm{~m}$ from urban areas exhibit better environmental conditions, since water is less susceptible to contamination by effluents (domestic and industrial). Moreover, coastal areas are also less subject to real estate speculation, tourism and aquatic recreational activities, which are incompatible with mariculture. Other aspects, such as access to the cultivation site, and distance between the seaweed farms and districts where those involved in the activity reside, were also deemed to be important assessment criteria. For example, distances greater than $4000 \mathrm{~m}$ from the residences of producers made the farm enterprise unfeasible, due to travelling times and elevated transport costs.

The proximity of natural seaweed beds is of fundamental importance in establishing the farms, since these locations can harbor species of commercial interest and can provide seeds and seaweed fragments for cultivation. Furthermore, they may serve as indicators of favorable environmental conditions for the growth and survival of the seaweeds. An additional factor evaluated was the distance of cultivation sites from estuaries. Areas close to estuaries are characterized by the presence of plume dilution resulting water that has lower salinity and higher turbidity. This decrease in salinity and increase in turbidity causes a decline in productivity and growth of the seaweeds.

On the Eastern coast, locations exhibiting the best combinations (scores) were located to the North (Touros, Rio do Fogo, Maxaranguape). These areas are suitable for seaweed farming due to conditions of shelter from the coast (wind, waves, current), operational ease (distance from roads, seaward and seaweed beds) and lower risk of pollution. The least viable areas were located in Natal and Tibau do Sul, with greater population density and extensive tourist activity. The location presenting the best environmental conditions on the Northern coast (score 8) was São Miguel de Touros. The lower scores obtained for some areas were a result of proximity to an estuary (Macau) and greater operating difficulties, such as distance from districts and roads (Reduto). Despite receiving scores between 5 and 7 , other regions in this part of the coast (Areia Branca, Guamaré and São Bento do Norte) were limited by socioeconomic factors (access roads and distances from districts) (Figure 2). The data obtained in this study constitute a suitable and efficient base for selecting promising seaweed cultivation sites. In addition, this study showed that GIS can be an excellent instrument for selecting potential seaweed cultivation sites and can be used as an example for other aquaculture sectors in Brazil.

\section{Acknowledgments}

The study was supported by the Food and Agriculture Organization of the United Nations, the Conselho Nacional de Desenvolvimento Cientifico e Tecnológico and the Ministério da Pesca e Aquicultura.

\section{References}

Banai-Kashani R 1989. A new method for site suitability analysis: the analytic hierarchy process. Environ Manage 13: 685-693.

Beveridge MCM, Ross LG, Mendoza QM 1994. Geographical Information Systems (GIS) for coastal aquaculture site selection and planning. In Koops K (org.) Proceedings of the IFS Workshop on Ecology of Marine Aquaculture. Stockholm: International Foundation for Science, p. 26-47.

Bezerra AF, Marinho-Soriano E 2010. Cultivation of the red seaweed Gracilaria birdiae (Gracilariales, Rhodophyta) in tropical waters of northeast Brazil. Biomass Bioenerg 34: 1813-1817.

Buschmann AH, Hernández-González MC, Varela D 2008. Seaweed future cultivation in Chile: perspectives and challenges. Int J Environment and Pollution 33: 432456.

Buitrago J, Rada M, Hernandez H, Buitrago E 2005. A singleuse site selection technique, using GIS, for aquaculture planning: Choosing locations for Mangrove oyster raft culture in Margarita Island, Venezuela Environ Manage 35: 544-556.

Felgueiras CA, Câmara G 1993. Sistema de Informações Geográficas do INPE 1. In: Assad ED, Sano EE (org.) Sistema de Informações Geográficas: aplicações na agricultura. Brasília: EMBRAPA/CPAC, p. 41-59.

Giap D, Yi Y, Yakupitiyage A 2005. GIS for land evaluation 
Use of geographic information systems (GIS) to identify adequate sites for cultivation of the seaweed Gracilaria birdiae in Rio Grande do Norte

for shrimp farming in Haiphong of Vietnam. Ocean Coast Manage 48: 5-63.

Marinho-Soriano E 1999. Species composition of seaweeds in Búzios beach, Rio Grande do Norte, Brazil. Seaweed Res Utiln 21: 9-13.

Marinho-Soriano E, Moreira WSC, Carneiro MAA 2006. Some aspects of the growth of Gracilaria birdiae (Gracilariales, Rhodophyta) in an estuary in northeast Brazil. Aquacult Int 14: 327-336.

Nath SS, Bolte JP, Ross LG, Aguilar-Manjarrez J 2000. Applications of geographical information systems (GIS) for spatial decision support in aquaculture. Aquacult Eng 23: 233-278.

Radiarta IN, Saitoh S-I, Miyazono A 2008. GIS-based multicriteria evaluation models for identifying suitable sites for Japanese scallop (Mizuhopecten yessoensis) aquaculture in Funka Bay, southwestern Hokkaido, Japan. Aquaculture 284: 127-135.

Radiarta IN, Saitoh S-I Yasui H 2011. Aquaculture site selection for Japanese kelp (Laminaria japonica) in southern Hokkaido, Japan, using satellite remote sensing and GIS-based models. ICES J Mar Sci 68: 773-780.

Saaty TL 1977 . A scaling method for priorities in hierarchical structures. J Math Psychol 15: 234-281.

Sulma S, Manopoo AKS, Hartuti M 2008. Identification of suitable area for seaweed culture in Bali Waters based on remote sensing satellite data. Int J Remote Sens 5: 57-66.

\section{*Correspondence}

\section{Eliane Marinho Soriano}

Departamento de Oceanografia e Limnologia, Universidade Federal do Rio Grande do Norte

Praia de Mãe Luiza, s/n, Via Costeira, 59014-100 Natal-RN, Brazil

eliane@ufrnet.br

Tel.: +558433424950

Fax: +558433424951 